\title{
Internal Friction and Compressive Deformation in the Primary Zone during the High-Speed Cutting of SiCp/Al Composites
}

Xiaoxuan Lin

Beijing Forestry University

Wenyuan Yang

Beijing Forestry University

Daochun Xu ( $\square$ xudaochun@bjfu.edu.cn )

Beijing Forestry University

Wenbin Li

Beijing Forestry University

Simin $\mathrm{Ma}$

Beijing Forestry University

\section{Research Article}

Keywords: Internal friction, Compressive deformation, SiCp/Al composites, High-speed cutting

Posted Date: June 1st, 2021

DOl: https://doi.org/10.21203/rs.3.rs-170479/v1

License: (9) This work is licensed under a Creative Commons Attribution 4.0 International License.

Read Full License 


\title{
Internal friction and compressive deformation in the primary zone during the high-speed cutting of $\mathrm{SiCp} / \mathrm{Al}$ composites
}

\author{
Xiaoxuan Lin ${ }^{\mathrm{a}, \mathrm{b}}$, Wenyuan Yang ${ }^{\mathrm{a}, \mathrm{c}}$, Daochun $\mathrm{Xu}^{\mathrm{a}, *}$, Wenbin $\mathrm{Li}^{\mathrm{a}}$, Simin $\mathrm{Ma}^{\mathrm{a}, \mathrm{c}}$ \\ ${ }^{a}$ School of Technology, Beijing Forestry University, Beijing 100083, China \\ ${ }^{\mathrm{b}}$ Shenzhen International Graduate School, Tsinghua University, Shenzhen 518055, China \\ ${ }^{c}$ School of Mechanical Engineering and Automation, Beihang University, Beijing 100191, China \\ *Corresponding author. E-mail: xudaochun@bjfu.edu.cn (Dr. Xu)
}

\begin{abstract}
The present work proposes that there is internal friction and compressive deformation in the primary zone. Mathematical model was established, in which the internal friction coefficient and some compressive characteristics of serrated chips were calculated. High-speed orthogonal cutting experiment was performed on $\mathrm{SiCp} / \mathrm{Al}$ composites at cutting speeds of $10-350 \mathrm{~m} / \mathrm{min}$ and feed rates of $0.07-0.12 \mathrm{~mm} / \mathrm{r}$. The internal friction and compressive deformation in the primary zone were investigated by combing results obtained in the experiments with the mathematical model. The internal friction coefficient (0.21-0.47), compressive stress (185.4 MPa-226.9 $\mathrm{MPa})$, and compressive strain rate $\left(0.013 \times 10^{4} / \mathrm{s}-0.554 \times 10^{4} / \mathrm{s}\right)$ increased with increasing cutting speed. However, the compression value $(17.3 \mu \mathrm{m}-50.0 \mu \mathrm{m})$ and compressive strain $(0.18-0.26)$ decreased with the cutting speed.
\end{abstract}

Keywords : Internal friction; Compressive deformation; SiCp/Al composites; High-speed cutting 


\begin{tabular}{|clcl|}
\hline \multicolumn{2}{|c|}{ Nomenclature } & & \\
$a_{c}$ & Depth of cutting $(\mathrm{mm})$ & $F_{T}$ & \multicolumn{1}{l|}{ Thrust force $(\mathrm{N})$} \\
$a_{w}$ & Width of cutting $(\mathrm{mm})$ & $F_{s}$ & Shear force $(\mathrm{N})$ \\
$L_{A B}$ & Shear plane length $(\mathrm{mm})$ & $N_{s}$ & Compression force $(\mathrm{N})$ \\
$\Delta X$ & Actual slip distance $(\mu \mathrm{m})$ & $F_{f}$ & Friction force $(\mathrm{N})$ \\
$\Delta Z$ & Theoretical slip distance $(\mu \mathrm{m})$ & $\Delta t$ & Unit cutting time $(\mathrm{s})$ \\
$\Delta Z-\Delta X$ & Compressive value $(\mu \mathrm{m})$ & $\alpha_{0}$ & Relief angle $\left(^{\circ}\right)$ \\
$H_{1}$ & Serrated chip root thickness $(\mu \mathrm{m})$ & $\phi$ & Shear angle $\left(^{\circ}\right)$ \\
$H_{2}$ & Serrated chip top thickness $(\mu \mathrm{m})$ & $\gamma_{0}$ & Rake angle $\left({ }^{\circ}\right)$ \\
$V$ & Cutting speed $(\mathrm{m} / \mathrm{min})$ & $\sigma_{s}$ & Compressive stress $(\mathrm{MPa})$ \\
$V_{c}$ & Chip outflow speed $(\mathrm{m} / \mathrm{min})$ & $\varepsilon_{s}{ }^{\prime}$ & Compressive strain rate $\left(\mathrm{s}^{-1}\right)$ \\
$V_{s}$ & Shear slip speed $(\mathrm{m} / \mathrm{min})$ & $\mu_{i n}$ & Internal friction coefficient \\
$f$ & Feed rate $(\mathrm{mm} / \mathrm{r})$ & $\tau_{s}$ & Shear stress $(\mathrm{MPa})$ \\
$F_{c}$ & Cutting force $(\mathrm{N})$ & $\varepsilon_{s}$ & Compressive strain \\
\hline
\end{tabular}

\section{Introduction}

Recently, metal matrix composites (MMCs) have received increasing attention from academia and industry. Among these MMCs, silicon carbide-reinforced aluminum matrix ( $\mathrm{SiCp} / \mathrm{Al}$ ) composites are considered especially promising materials due to their superior properties compared with those of conventional materials. These composites are characterized by good dimensional stability, lower coefficients of thermal expansion, high specific strength[1-2] and good wear resistance which can increase with the rising volume fraction of $\mathrm{SiC}$ particles [3]. High dislocation density[4], crystalline refinement and load transfer[5] are the main strengthening mechanisms of $\mathrm{SiCp} / \mathrm{Al}$ composites. These materials are widely used in (for example) aerospace components, advanced weapons, optical components, automotive manufacturing, precision instruments, and electronics [1,6-9]. In addition, $\mathrm{SiCp} / \mathrm{Al}$ composites will produce serrated chips during the cutting process, which lead to high-frequency fluctuations of the cutting force, and exacerbate the wear and damage of the tool. Therefore, machining of SiCp/Al composites is extremely difficult[10], and results in severe tool wear as well as poor tool durability and surface integrity [11-13].

Friction phenomena within the tool-chip interface has been well investigated [14-16]. Behera et al.[16] proposed dual contact zone theory (sticking-sliding) instead of single contact zone theory to model the chip-tool contact relation. Frictional forces has been put forward to consist of sliding friction and rolling friction [17]. Smolenicki et al.[18]developed a newly in-process tribometer for quick characterization of friction coefficient in orthogonal cutting. Grzesik et al. [19] proposed a new friction model for the oblique cutting, extending the simple Merchant's model by taking the influence of tool wear into consideration. Nair et al.[20] determined the effects of the tribological behavior of $\mathrm{SiC}$ particles on billet deformation characteristics. The effect of applied pressure on the tribological behavior of SiCp reinforced aluminum alloy has been investigated[21]. Xu et al. [22] proposed the 
shear slip distance and established a high-speed orthogonal model of shear slip deformation which can be used to calculate the important parameters of chip formation. The cutting force prediction in machining of MMCs was also investigated [17,23-24].

Two main theories for serrated chip formation mechanism are widely investigated: period brittle fracture [25] and adiabatic shear theory [26]. Duan et al. [27] divided the deformation process of the shear zone into four stages, namely the: occurrence of shear localization, generation of shear localization, crack initiation, and crack propagation. According to Huang et al. [28], the growth and coalescence of voids and cracks lead to sudden shear fracture on the free surface of chips; as a result, serrated chips are formed via the sliding of material. The formation of serrated chips was also attributed to the deformation and the propagation of a crack in the primary shear zone [29]. Du et al. [30] proposed that the $\mathrm{SiCp} / \mathrm{Al}$ composites chip-formation mechanism was based on severe plastic deformation of the $\mathrm{Al}$ matrix, the contact position between the $\mathrm{SiC}$ particles and the diamond grit, and the removal mode of these particles.

Few studies have considered the existence of internal friction in the primary zone. During the cutting process, material undergoes shear slip in the primary zone and there should be relative movement within material. Therefore, the present work proposes there is friction in the primary zone, which is referred to that produced by the slip movement in the shear plane and called internal friction. For serrated chip, shear slip is insufficient to explain actual sawtooth shape independently and pressure should be present during cutting. Therefore, the present work proposes the formation of sawtooth is supposed to be accompanied by compressive deformation, there is compressive deformation in the primary zone. Understanding more about these may provide technical basis for controlling chip serration degree to enhance the surface quality of the workpiece. A mathematical model was developed and highspeed orthogonal cutting experiments of $\mathrm{SiCp} / \mathrm{Al}$ composites are conducted. Analysis and discussion about internal friction, compressive deformation in primary zone were investigated, enriching the understanding of them.

\section{Mathematical model for serrated chip}

According to Merchant's theory, the shear angle can be measured from the chip thickness:

$$
\phi=\arctan \left[a_{\mathrm{C}} \cos \gamma_{0} /\left(H_{1}-a_{\mathrm{C}} \sin \gamma_{0}\right)\right]
$$

According to the geometric relationship shown in Fig. 1, the shear stress on shear plane AB can be obtained from:

$$
\tau_{A B}=F_{S} /\left(L_{A B} \times a_{w}\right)=\sin \phi\left(F_{C} \cos \phi-F_{T} \sin \phi\right) /\left(a_{c} a_{w}\right)
$$




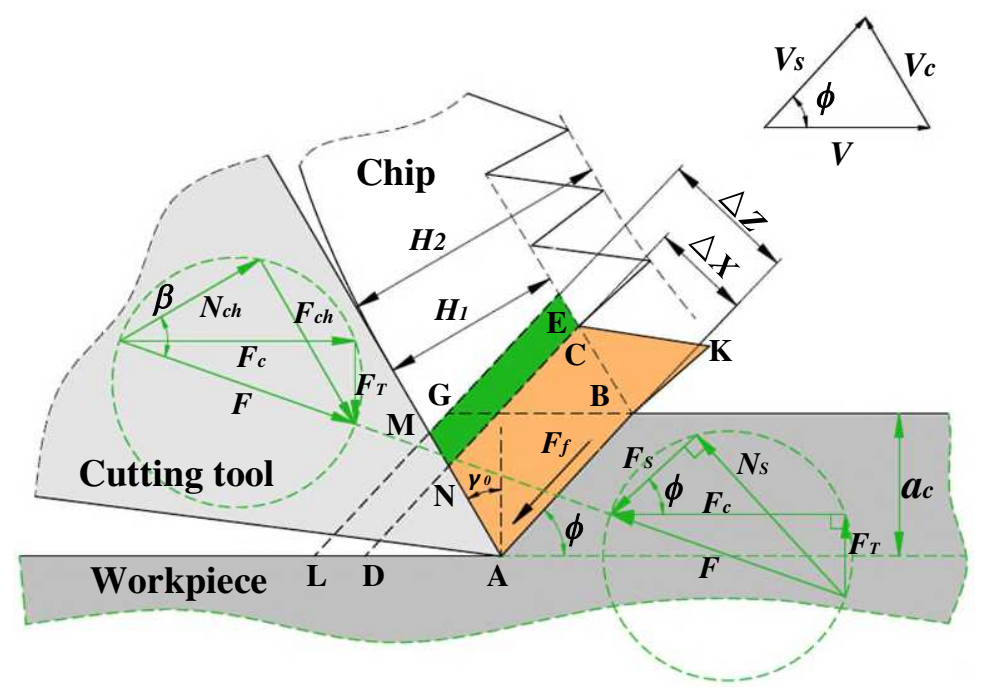

Fig. 1. Mathematical model for serrated-chip

The distance between two actual slip lines is referred to as the actual slip distance(considering compressive deformation). Similarly, the distance between two theoretical slip lines (without considering compressive deformation) is referred to as the theoretical slip distance. According to the principle of volume constancy, the area before and after compression is the same, hence:

$$
\begin{gathered}
S_{C E M N}=S_{\triangle B C K} \\
\Delta Z=\Delta X+\left(H_{2}-H_{1}\right) \Delta X /\left(2 H_{1}\right)=\left(H_{2}+H_{1}\right) \Delta X /\left(2 H_{1}\right)
\end{gathered}
$$

The compressive stress can be calculated from:

$$
\sigma_{s}=N_{S} /\left(L_{A B} a_{W}\right)=\sin \phi\left(F_{C} \sin \phi+F_{T} \cos \phi\right) /\left(a_{C} a_{W}\right)
$$

The compressive strain can be expressed as follows:

$$
\varepsilon_{s}=(\Delta Z-\Delta X) / \Delta Z=\left[\left(H_{2}+H_{1}\right) \Delta X / 2 H_{1}-\Delta X\right] /\left[\left(H_{2}+H_{1}\right) \Delta X / 2 H_{1}\right]=\left(H_{2}-H_{1}\right) /\left(H_{2}+H_{1}\right)
$$

Set time of the process that initial compressive strain increase from 0 to $\varepsilon_{s}$ as $\Delta t$, the compressive strain rate can be written as:

$$
\varepsilon_{s}{ }^{\prime}=\Delta \varepsilon / \Delta \mathrm{t}=(\varepsilon V) / L_{A L}=(\varepsilon V) /(\Delta Z / \sin \phi)=\left[10\left(H_{2}-H_{1}\right) V \cdot H_{1} \sin \phi\right] /\left[3\left(H_{1}+H_{2}\right)^{2} \Delta X\right]
$$

The internal friction coefficient in the primary shear zone can be calculated as follows:

$$
\begin{gathered}
\mu_{i n}=F_{f} / F_{n}=\left(\tau_{s} \cdot A_{\tau}\right) /\left(\sigma_{s} \cdot A_{\sigma}\right) \text { and } A_{\tau}=A_{\sigma} \\
\mu_{i n}=\tau_{s} / \sigma_{s}
\end{gathered}
$$

The internal friction coefficient and compressive characteristics including the compression value, compressive stress, strain, and strain rate are able to be calculated when the forces and some chip parameters are known. The cutting force and thrust force can be measured by the dynamometer during the experiment. Furthermore, the slip distance and chip thickness can be determined from the scanning electron micrograph of the chip. The further 
investigation is in section 4 .

\section{Experiment and methods}

\subsection{Material}

$\mathrm{SiCp} / \mathrm{Al}$ (30\% volume fraction) composites was used to perform high-speed orthogonal cutting experiments. The $\mathrm{SiCp} / \mathrm{Al}$ (30p) composite was obtained via stir casting. This composite was machined into workpieces each with a diameter and thickness of $80 \mathrm{~mm}$ and $2 \mathrm{~mm}$, respectively. A $12 \mathrm{~mm}$-center-hole, for mounting the workpieces on the three-jaw chuck using custom fixtures, was also machined into the workpieces.

\subsection{High-speed orthogonal cutting experiment}

The high-speed orthogonal cutting experiment was performed under dry conditions on a DMG-CTX 310 CNC lath, (see Fig. 2 for the experimental setup details). SECO-SCFCL 1212F09 was selected as the tool holder. This holder mounted the cutting tool SECO-CCMW 09T302F-L1 (PCD 20) at $0^{\circ}$ rake angle, $0^{\circ}$ inclination angle, and $7^{\circ}$ relief angle. The cutting force and thrust force were measured by a Kistler 9257B dynamometer. The dynamometer is quartz three-component dynamometer for measuring the three orthogonal components of a force, consisting of four three-component force sensors and can perform multicomponent measurements of forces. A transverse feed, where the feed motion is perpendicular to the spindle axis, was employed. The diameter of the cutting workpiece changed continuously during the feeding process. In order to ensure a constant cutting line speed, the spindle speed was set to constantly vary.

The experimental parameters are listed in Table 1. All the produced chips and records of cutting forces during the experiments were collected and sorted, thereby providing the parameters for the established model.

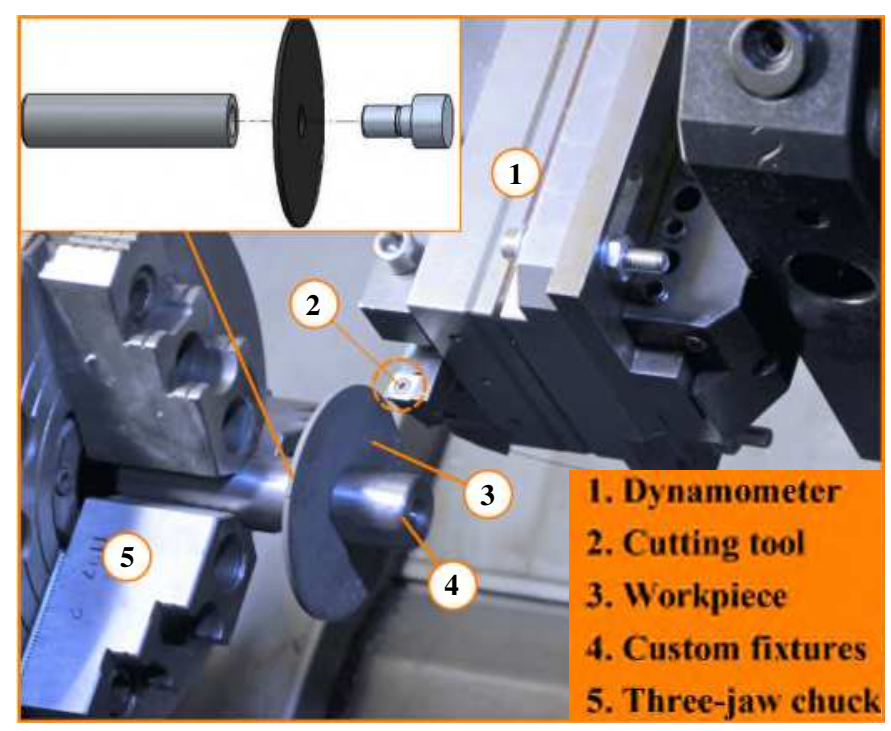

Fig. 2. Experimental setup details. 


\begin{tabular}{cccc}
\hline Group & $\begin{array}{c}\text { Cutting Speed } \\
(\mathrm{m} / \mathrm{min})\end{array}$ & $\begin{array}{r}\text { Feed rate } f \\
(\mathrm{~mm} / \mathrm{rev})\end{array}$ & $\begin{array}{c}\text { Width of cutting } a_{w} \\
(\mathrm{~mm})\end{array}$ \\
\hline 1 & $10,30,50$, & 0.07 & 2 \\
& $150,250,350$ & & 2 \\
2 & $10,30,50$, & 0.12 & 2 \\
\hline
\end{tabular}

Table 1. Experimental parameters

\subsection{Chip treatment and measurement}

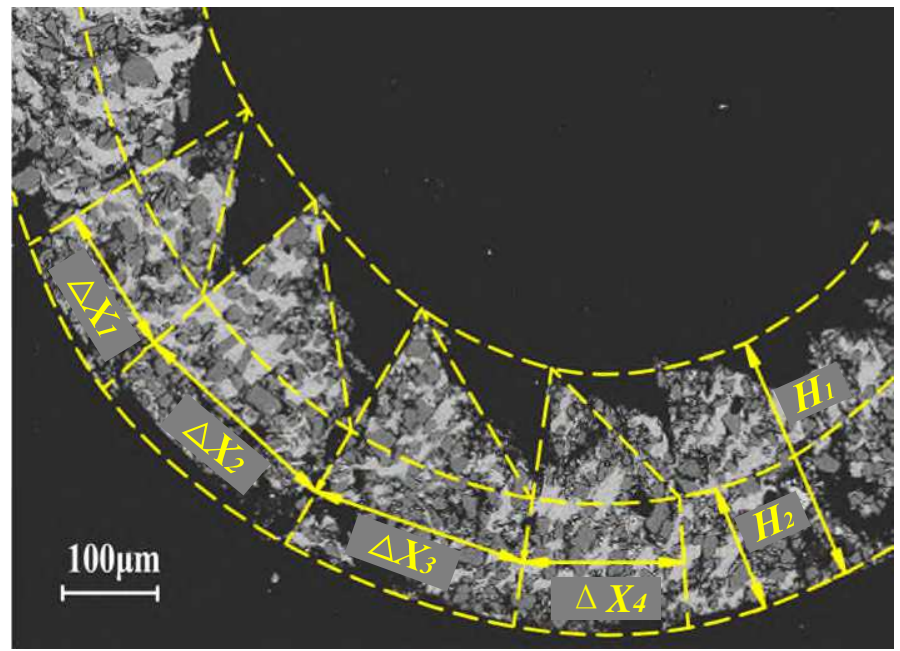

Fig. 3. Schematic showing chip measurement.

The chips associated with different cutting conditions were collected and fabricated into samples (after grinding, polishing, and corroding). These samples were then observed with a Merlin field emission scanning electron microscope. As shown in Fig. 3, the actual slip distance and chip thickness values were obtained from the scanning electron micrograph of the chip. The average values for multiple measurements were taken as the final values.

\section{Results and discussion}

\subsection{Basic characteristics}

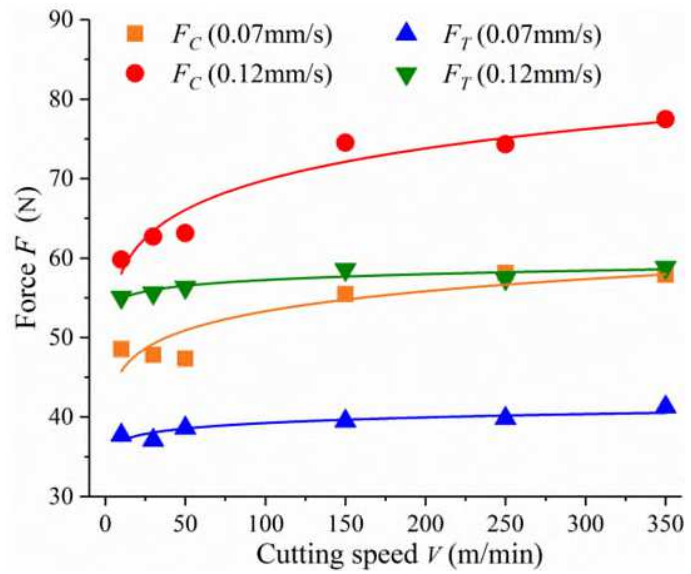

(a)

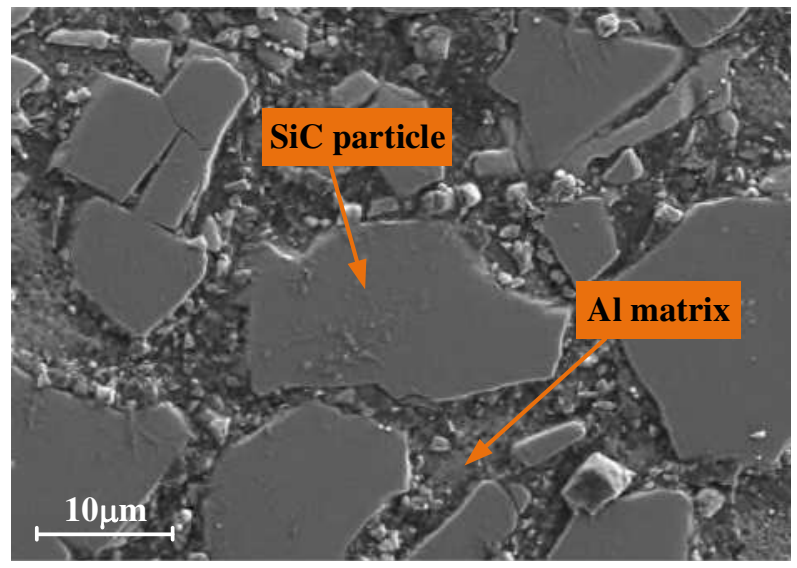

(b) 


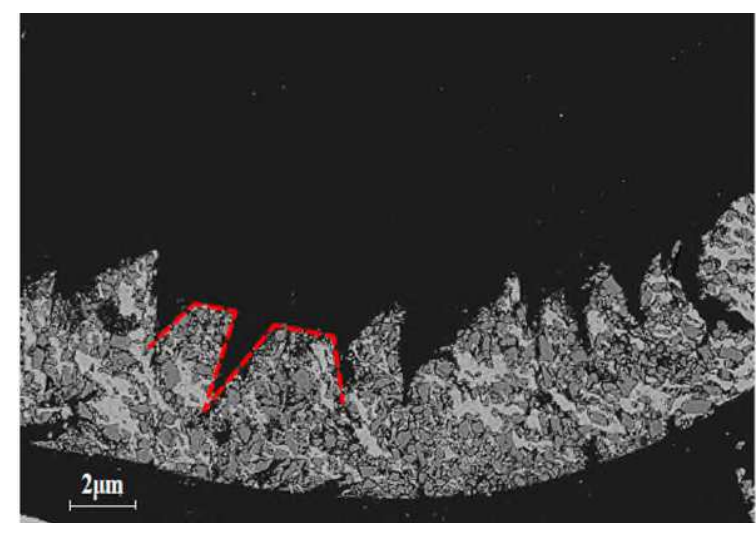

(c)

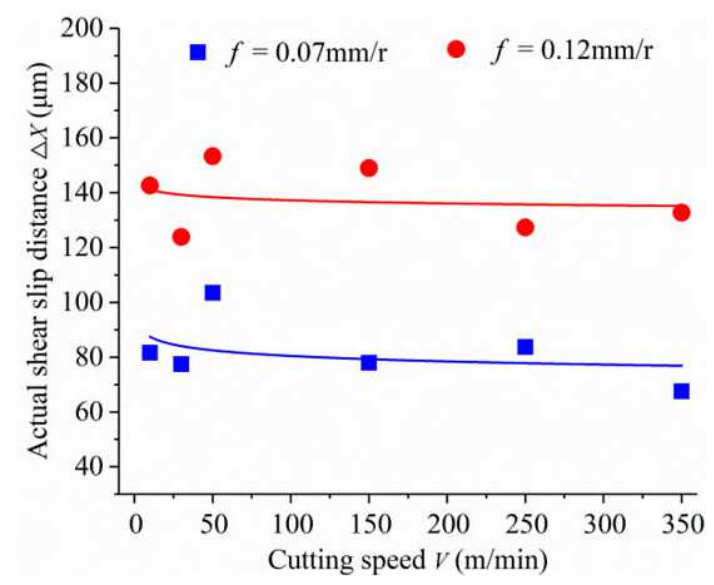

(e)

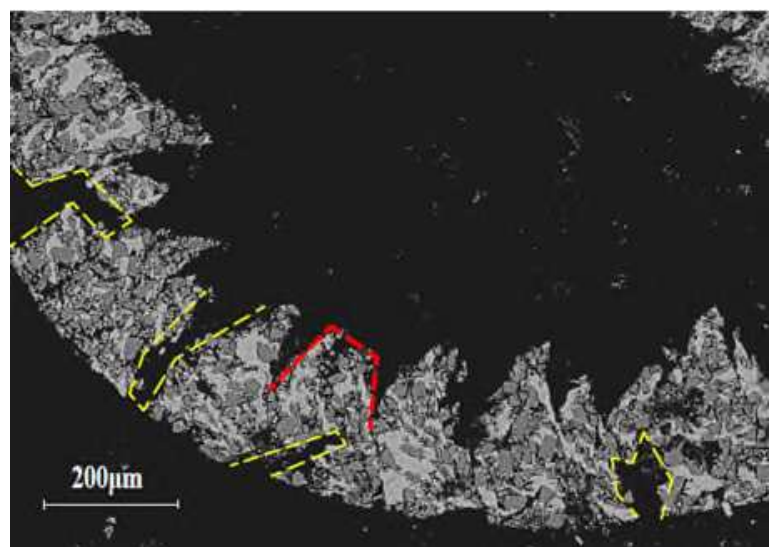

(d)

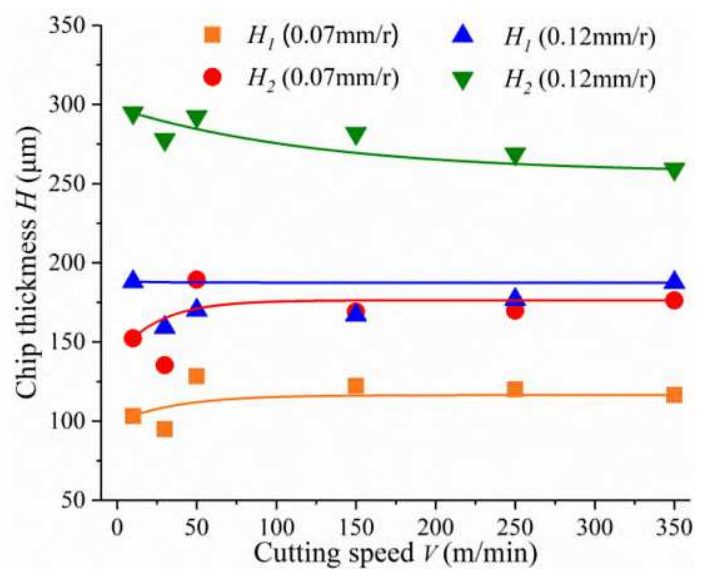

(f)

Fig. 4. Basic parameters: (a) force, (b) SEM image of chip subjected to $0.07 \mathrm{~mm} / \mathrm{r}$ and $30 \mathrm{~m} / \mathrm{min}$ after the experiment, (c)、(d) SEM image of chip subjected to $0.12 \mathrm{~mm} / \mathrm{r}$ and $30 \mathrm{~m} / \mathrm{min}$, (e) actual slip distance and (f) chip thickness.

\subsubsection{Force}

The main cutting force and the thrust force range from $48.6 \mathrm{~N}$ to $77.5 \mathrm{~N}$ and $37.7 \mathrm{~N}$ to $58.8 \mathrm{~N}$, respectively. When the cutting speed increases, the thrust force is relatively stable, whereas the cutting force increases. Both forces increase with increasing feed rate. In the first deformation zone, a relatively high cutting speed can simultaneously induce the strain hardening effect and the thermal softening effect. However, the hardening effect is stronger than the softening effect, thereby resulting in an increasing force.

\subsubsection{Chip characteristics}

\subsubsection{Chip features}

Fig. $4 \mathrm{~b}$ shows the microstructure of the $\mathrm{SiCp} / \mathrm{Al}$ (30p) composites after the experiment, where SiC particles fragment into irregular particles. Moreover, this also shows that the SiC particles have undergone considerable changes during the cutting process and have a significant effect on this process. There is interaction between $\mathrm{SiC}$ particles and aluminum matrix, and interaction also exists between SiC particles, which causing the shape of 
serrated-chip to be unique. As shown in Fig. 4c and Fig. 4d, the shape of sawtooth is irregular because of the influence of SiC particles. Some of the sawtooth's tips are not sharp and even flat (marked in red dotted line) and some of the sawtooth's outlines are incomplete and even broken (marked in yellow dotted line).

\subsubsection{Slip distance}

The actual slip distance, which represents the size of the sawtooth, is determined via the method depicted in Fig. 3. As shown in Fig. $4 \mathrm{e}$, feed rates of $0.07 \mathrm{~mm} / \mathrm{r}$ and $0.12 \mathrm{~mm} / \mathrm{r}$ yield, $\Delta X$ of $67.5 \mu \mathrm{m}-103.4 \mu \mathrm{m}$ and $127.3 \mu \mathrm{m}-$ $153.3 \mu \mathrm{m}$, respectively. $\Delta X$ increases (in general) with the feed rate, indicating that increasing feed rate results in more-sufficiently-formed sawtooth.

\subsubsection{Chip thickness}

As shown in Fig. 4f, a feed rate of (i) $0.07 \mathrm{~mm} / \mathrm{r}$ yields $H_{1}: 94.8 \mu \mathrm{m}-128.4 \mu \mathrm{m}$ and $H_{2}: 135.3 \mu \mathrm{m}-189.4 \mu \mathrm{m}$, (ii) $0.12 \mathrm{~mm} / \mathrm{r}$ yields $H_{1}: 159.1 \mu \mathrm{m}-215.9 \mu \mathrm{m}$ and $H_{2}: 259.2 \mu \mathrm{m}-294.7 \mu \mathrm{m}$. The chip thickness is positively correlated with the feed. A transverse-feed method is employed and, hence, a large feed results in a large depth of cutting, and an increase in the chip thickness. In terms of the cutting-speed dependence, the chip thickness varies more significantly at low cutting speeds than at higher speeds. Furthermore, a sawtooth-size limit is observed, i.e., the thickness remains almost constant after reaching a certain value, owing possibly to the obstruction of SiC. When the cutting speed increases, the cutting temperature increases and the thermal softening effect is strengthened, resulting in improved sawtooth production. However, when the sawtooth-size threshold is reached, the chipthickness limit is also reached and the thickness remains almost constant thereafter.

\subsection{Compressive deformation}

After obtaining the basic parameters, the compressive deformation characteristics (see Fig. 5) can be obtained with assistance of the theoretical model.

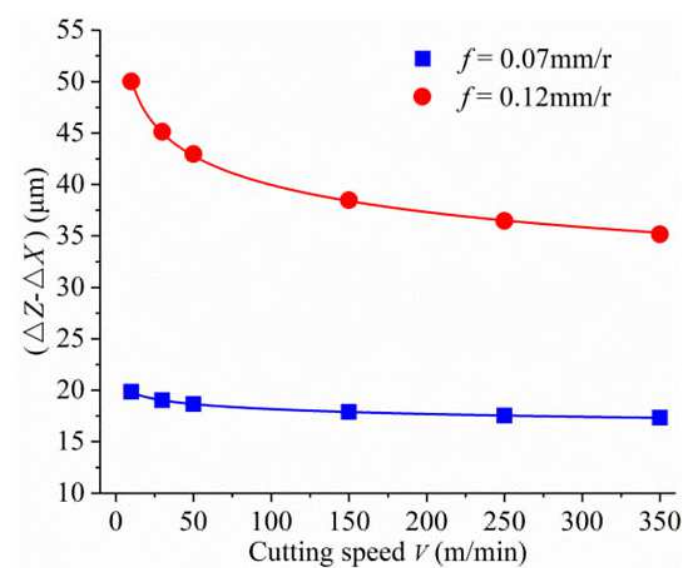

(a)

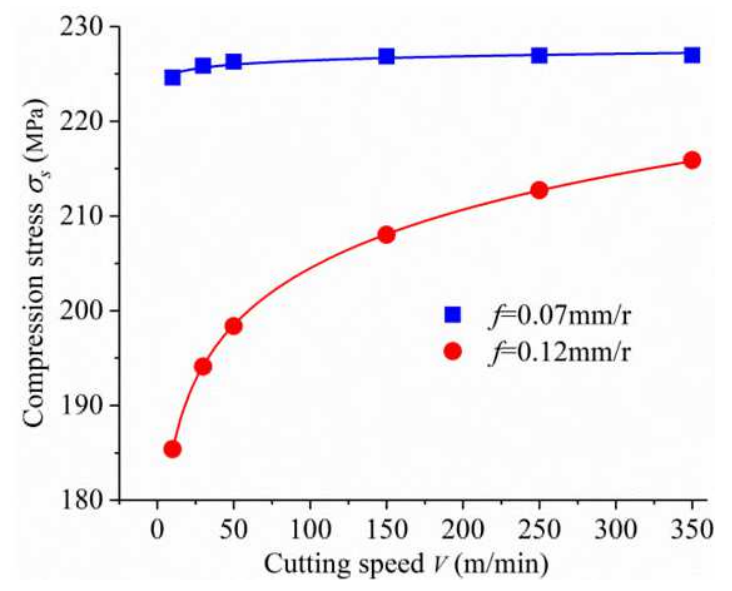

(b) 


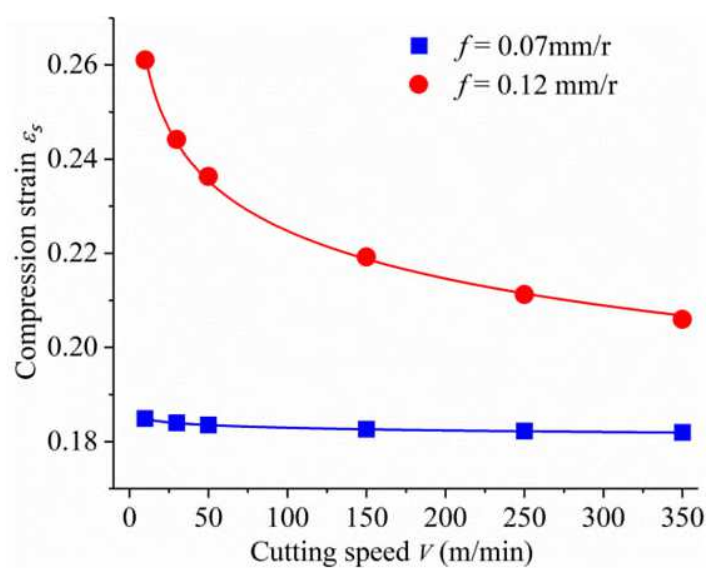

(c)

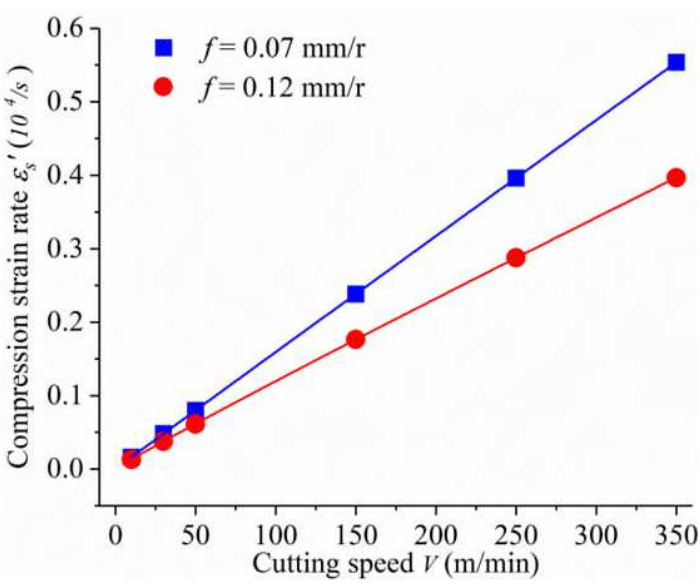

(d)

Fig. 5. Values of the (a) compressive value, (b) compressive stress, (c) compressive strain, and (d) compressive strain rate

\subsubsection{Compression value}

Fig. 5a shows the compression value, which reflects the degree of compressive deformation. Values of 17.3 $\mu \mathrm{m}-50.0 \mu \mathrm{m}$ are obtained for cutting speeds and feed rates of $10-350 \mathrm{~m} / \mathrm{min}$ and $0.07-0.12 \mathrm{~mm} / \mathrm{r}$, respectively. The compressive value in practice is greater than 0 , showing compressive deformation. There has already been known to be shear deformation in the primary zone. Therefore, the fact that the primary zone undergoes simultaneous compressive deformation and shear deformation reflects internal friction in this zone.

The values increase with increasing feed rate. Similarly, the magnitude of the force increases with increasing feed rate (as shown in Fig. 4a), leading to intensified extrusion of the $\mathrm{SiC}$ particles against the $\mathrm{Al}$ matrix and interactions between these particles. This intensification enhances the pressing effect exerted by the formed chips on the on-forming chips, contributing to an increase in the degree of compressive deformation. However, the values remain nearly constant with increasing cutting speed. According to Eq. (3), the compressive value can be expressed in terms of actual slip distance, chip root thickness and top thickness. These three parameters remain almost constant when the cutting speed increases (see Fig. 4e and 4f) and, as a result, the compressive value is also (almost) constant.

\subsubsection{Compressive stress}

The compressive stress ranges from 185.4 MPa to 226.9 MPa, and decreases with increasing feed rate, but increases with increasing cutting speed (see Fig. 5b). According to Eq. (4), this stress is closely correlated with the cutting force (i.e., the main cutting force and the thrust force (Fig. 4a)) and, consequently, increases with increasing cutting speed. Owing to the transverse-feed method, a larger feed rate results in greater depth of cutting (than a smaller feed rate). This leads to a dilution or reduction in the force exerted by the $\mathrm{SiC}$ particles on the shear plane, 
thereby resulting in a reduction in the compressive stress.

\subsubsection{Compressive strain}

Compressive strain values of $0.18-0.26$ occur at cutting speeds and feed rates of $10-350 \mathrm{~m} / \mathrm{min}$ and $0.07-0.12$ $\mathrm{mm} / \mathrm{r}$, respectively (see Fig. 5c). According to Eqs. (3) and (5), both the compressive value and the compressive strain are calculated from the chip thickness, and are described by similar expressions. Therefore, the change law explanations and curve trends of the compressive strain are similar to those of compressive value.

\subsubsection{Compressive strain rate}

The compressive strain rate $\left(0.013 \times 10^{4} / \mathrm{s}-0.554 \times 10^{4} / \mathrm{s}\right)$ increases significantly with increasing cutting speed and decreases with increasing feed rate (see Fig. 5d). According to Eq. (6), the compressive strain rate is calculated from the actual slip distance, chip thickness, and cutting speed. Both the actual slip distance and chip thickness change only slightly with the speed (see Fig. $4 \mathrm{e}$ and $4 \mathrm{f}$ ) and, therefore the compressive strain rate exhibits a nearly positive linear dependence on the speed. As the feed rate increases, the hardening effect overcomes the thermal softening effect, leading to a reduction in the strain rate. In addition, due to the transverse feed, the amount of workpiece that must be simultaneously removed by the tool increases when the feed rate increases. This leads to reductions in the removal speed and, accordingly, the strain rate.

\subsection{Shear stress and internal friction coefficient}

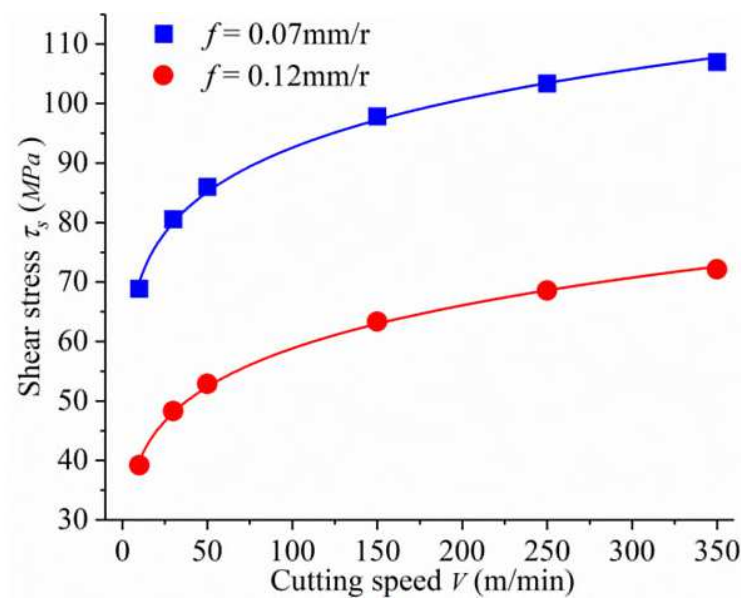

(a)

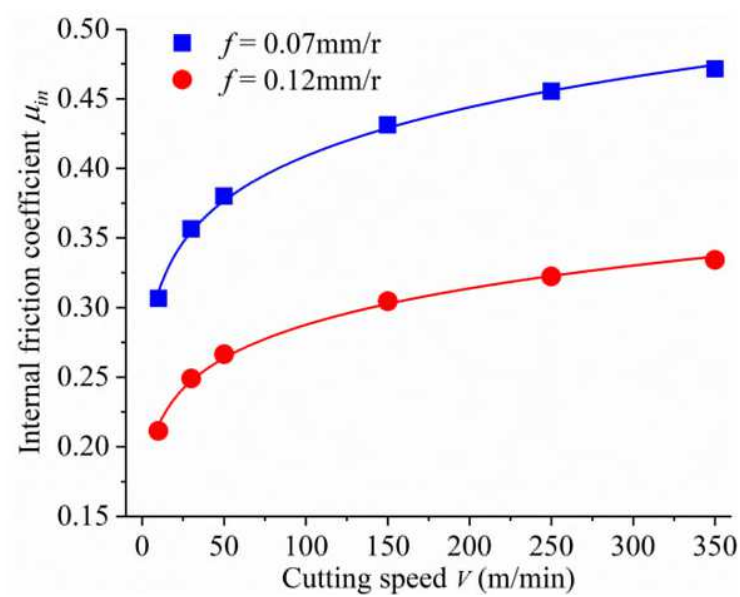

(b)

Fig. 6. (a) Shear stress and (b) internal friction coefficient.

\subsubsection{Shear stress}

Figure 6a shows that, for a given feed rate, the shear stress increases from 39.2 MPa to 107.0 MPa with increasing cutting speed and, for a given cutting speed, decreases with decreasing feed rate. Similarly, the measured force would decrease, because the proportion of the force that $\mathrm{SiC}$ particles exert on the tool decreases with 
increasing feed rate, thereby leading to a reduction in the calculated shear stress. However, when the cutting speed rises, the hardening effect overcomes the softening effect and, consequently, the shear stress increases.

\subsubsection{Internal friction coefficient}

The internal friction coefficient of the primary zone increases from 0.21 to 0.47 (Fig. 6b). In fact, for a given feed rate, $\mu_{i n}$ increases with increasing cutting speed and, for a given cutting speed, decreases with increasing feed rate. The temperature of the primary shear zone increases with rising cutting speed. The material internal flow, extrusion of $\mathrm{SiC}$ particles against the $\mathrm{Al}$ matrix, and interaction inside the $\mathrm{SiC}$ particles become quite complex, owing to this increase. As a result, the friction effect is strengthened, leading to an increase in the internal friction coefficient. Furthermore, the depth of cutting increases with increasing feed rate, leading to an increase in the amount of workpiece that must be simultaneously removed. The corresponding intensity of shear slip and relative movement in the primary deformation zone decreases, contributing to a small internal coefficient.

\section{Conclusions}

The present work proposes that there is internal friction and compressive deformation in the primary zone. A mathematical model is established which gives methods for calculating internal friction coefficient and compressive characteristics of serrated chip. High-speed orthogonal cutting experiments on $\mathrm{SiCp} / \mathrm{Al}$ composites are performed at cutting speeds of $10-350 \mathrm{~m} / \mathrm{min}$ and feed rates of $0.07-0.12 \mathrm{~mm} / \mathrm{r}$.

According to the experimental results, affected by $\mathrm{SiC}$ particles, the shape of sawtooth is irregular and the stress will be altered by the change in the force exerted by the $\mathrm{SiC}$ particles. The internal friction coefficient of the primary zone ranges from 0.21 to 0.47 , increases with the cutting speed, and decreases with the feed rate. When the cutting speed increases, the compressive stress (185.4 MPa-226.9 MPa) and compressive strain rate $\left(0.013 \times 10^{4} / \mathrm{s}-\right.$ $\left.0.554 \times 10^{4} / \mathrm{s}\right)$ increase, whereas the compression value $(17.3 \mu \mathrm{m}-50.0 \mu \mathrm{m})$ and compressive strain $(0.18-0.26)$ decrease.

\section{Acknowledgments}

This work was supported by the National Natural Science Foundation of China (51875045). We thank Liwen Bianji, Edanz Editing China (www.liwenbianji.cn/ac), for editing the English text of a draft of this manuscript

\section{Ethical Approval:}

This research does not involve human participants or animals, thus no ethical approval and patient consent are required.

\section{Consent to Participate:}

Not applicable. 


\section{Consent to Publish:}

Not applicable.

\section{Authors Contributions:}

Xiaoxuan Lin: Formal analysis, Investigation, Writing - Original Draft, Writing - Review \& Editing.

Wenyuan Yang: Methodology, Investigation, Writing - Original Draft.

Daochun Xu: Conceptualization Ideas, Supervision, Funding acquisition.

Wenbin Li: Supervision.

Simin Ma: Writing - Review \& Editing.

\section{Funding:}

This work was supported by the National Natural Science Foundation of China (51875045).

\section{Competing Interests:}

The authors declare that they have no competing interests.

\section{Availability of data and materials:}

The datasets used or analyzed during the current study are available from the corresponding author on reasonable request.

\section{References}

[1] Xiang JF, Xie LJ, Gao FN, Yi J, Pang SQ, Wang XB. Diamond tools wear in drilling of SiCp /Al matrix composites containing Copper. Ceram Int 2018;44:5341-51.

[2] Feng PF, Liang GQ, Zhang JF. Ultrasonic vibration-assisted scratch characteristics of silicon carbidereinforced aluminum matrix composites. Ceram Int 2014;40:10817-23.

[3] Kumar S, Balasubramanian V. Effect of reinforcement size and volume fraction on the abrasive wear behaviour of AA7075 Al/SiCp P/M composites-A statistical analysis. Tribol int 2010;43:414-22.

[4] Zhang F, Sun PF, Li XC, Zhang GD. A comparative study on microplastic deformation behavior in a

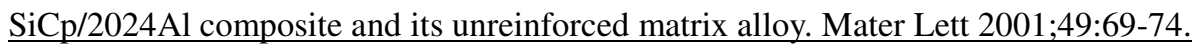

[5] Cheng NP, Zeng SM, Liu Y. Preparation, microstructures and deformation behavior of SiCP/6066Al composites produced by PM route. J Mater Process Tech 2008;202:27-40.

[6] Naher S, Brabazon D, Looney L. Computational and experimental analysis of particulate distribution during Al-SiC MMC fabrication. Compos Part A-Appl S 2007;38:719-29.

[7] Han JJ, Hao XQ, Li L, Wu Q, He N. Milling of high volume fraction SiCp/Al composites using PCD tools 
with different structures of tool edges and grain sizes. Int J Adv Manuf Technol 2017;92:1875-82.

[8] Zhou L, Wang Y, Ma ZY, Yu XL. Finite element and experimental studies of the formation mechanism of edge defects during machining of SiCp/Al composites. Int Mach Tool Manu 2014;84:9-16.

[9] Teng XY, Chen WQ, Huo DH, Shyha I, Lin C. Comparison of cutting mechanism when machining micro and nano-particles reinforced SiC/Al metal matrix composites. Compos Struct 2018;203:636-47.

[10] Sahoo AK, Pradhan S. Modeling and optimization of Al/SiCp MMC machining using Taguchi approach. Measurement 2013;46:3064-72.

[11] Tosun G, Muratoglu M. The drilling of an $\mathrm{Al} / \mathrm{SiC}$ metal-matrix composites, Part I: microstructure. Compos Sci Technol. 2004;64:299-308.

[12] Ciftci I, Turker M, Seker U. Evaluation of tool wear when machining SiCp-reinforced Al-2014 alloy matrix composites. Mater Design 2004;25:251-55.

[13] Iuliano L, Settineri L, Gatto A. High-speed turning experiments on metal matrix composites. Compos Part AAppl S 1998;29:1501-09.

[14] Puls H, Klocke F, Lung D. Experimental investigation on friction under metal cutting conditions. Wear 2014;310:63-71.

[15] Bahi S, Nouari M, Moufki A, El Mansori M, Molinari A. Hybrid modelling of sliding-sticking zones at the tool-chip interface under dry machining and tool wear analysis. Wear 2012;286-287:45-54.

[16] Behera BC, Ghosh S, Rao PV. Modeling of cutting force in MQL machining environment considering chip tool contact friction. Tribol int 2018;117:283-95.

[17] Wang JF, Zuo JF, Shang Z, Fan XL. Modeling of cutting force prediction in machining high-volume SiCp/Al composites. Appl Math Model 2019;70:1-17.

[18] Smolenicki D, Boos J, Kuster F, Roelofs H, Wyenc CF. In-process measurement of friction coefficient in orthogonal cutting. CIRP Ann-Manuf Techn 2014;63:97-100.

[19] Grzesik W, Kowalczyk D, Żak K. A new mechanistic friction model for the oblique cutting with tool wear effect. Tribol int 2013;66:49-53.

[20] Nair F, Karamis MB. An investigation of the tribological interaction between die damage and billet deformation during MMC extrusion. Tribol int 2010;43:347-355.

[21] Rao RN, Das S. Effect of applied pressure on the tribological behaviour of SiCp reinforced AA2024 alloy. Tribol int 2011;24:454-62.

[22] Xu DC, Feng PF, Li WB, Ma Y, Liu B. Research on chip formation parameters of aluminum alloy 6061-T6 
based on high-speed orthogonal cutting model. Int J Adv Manuf Technol 2014;72:955-62.

[23] Dabade UA, Dapkekar D, Joshi SS. Modeling of chip-tool interface friction to predict cutting forces in machining of Al/SiCp composites. Int J Mach Tool Manu 2009;49:690-700.

[24] Pramanik A, Zhang LC, Arsecularatne JA. Prediction of cutting forces in machining of metal matrix composites. Int J Mach Tool Manu 2006;46:1795-1803.

[25] Shaw MC, Vyas A. Chip Formation in the Machining of Hardened Steel. CIRP Ann - Manuf Techn 1993;42:29-33.

[26] Komanduri R, Turkovich BFV. New observations on the mechanism of chip formation when machining titanium alloys. Wear 1981;69:179-88.

[27] Duan CZ, Sun W, Fu C, Zhang FY. Modeling and simulation of tool-chip interface friction in cutting Al/SiCp composites based on a three-phase friction model. Int J Mech Sci 2018;142-143:384-96.

[28] Huang ST, Yu XL, Wang FS, Xu LF. A study on chip shape and chip-forming mechanism in grinding of high volume fraction $\mathrm{SiC}$ particle reinforced Al-matrix composites. Int J Adv Manuf Technol 2015;80:1927-32.

[29] Ducobu F, Rivière-Lorphèvre E, Filippi E. Experimental contribution to the study of the Ti6Al4V chip formation in orthogonal cutting on a milling machine. Int J Mat Form 2015;8:455-68.

[30] Du JG, Zhou L, Li JG, Yao YX. Analysis of Chip Formation Mechanism in Mill-grinding of SiCp/Al Composites. Mater Manuf Process 2014;29:11-12. 
Figures

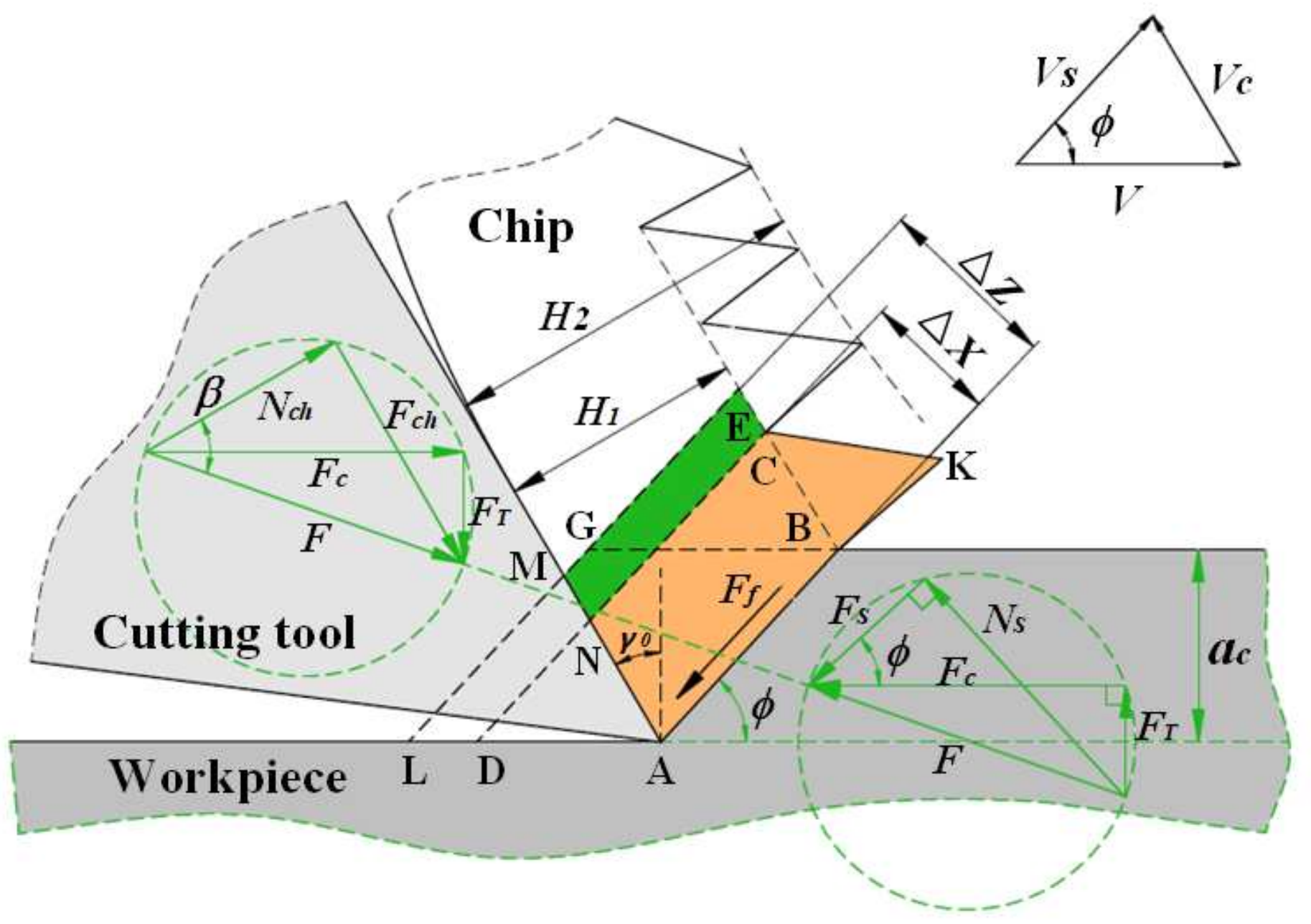

Figure 1

Mathematical model for serrated-chip 


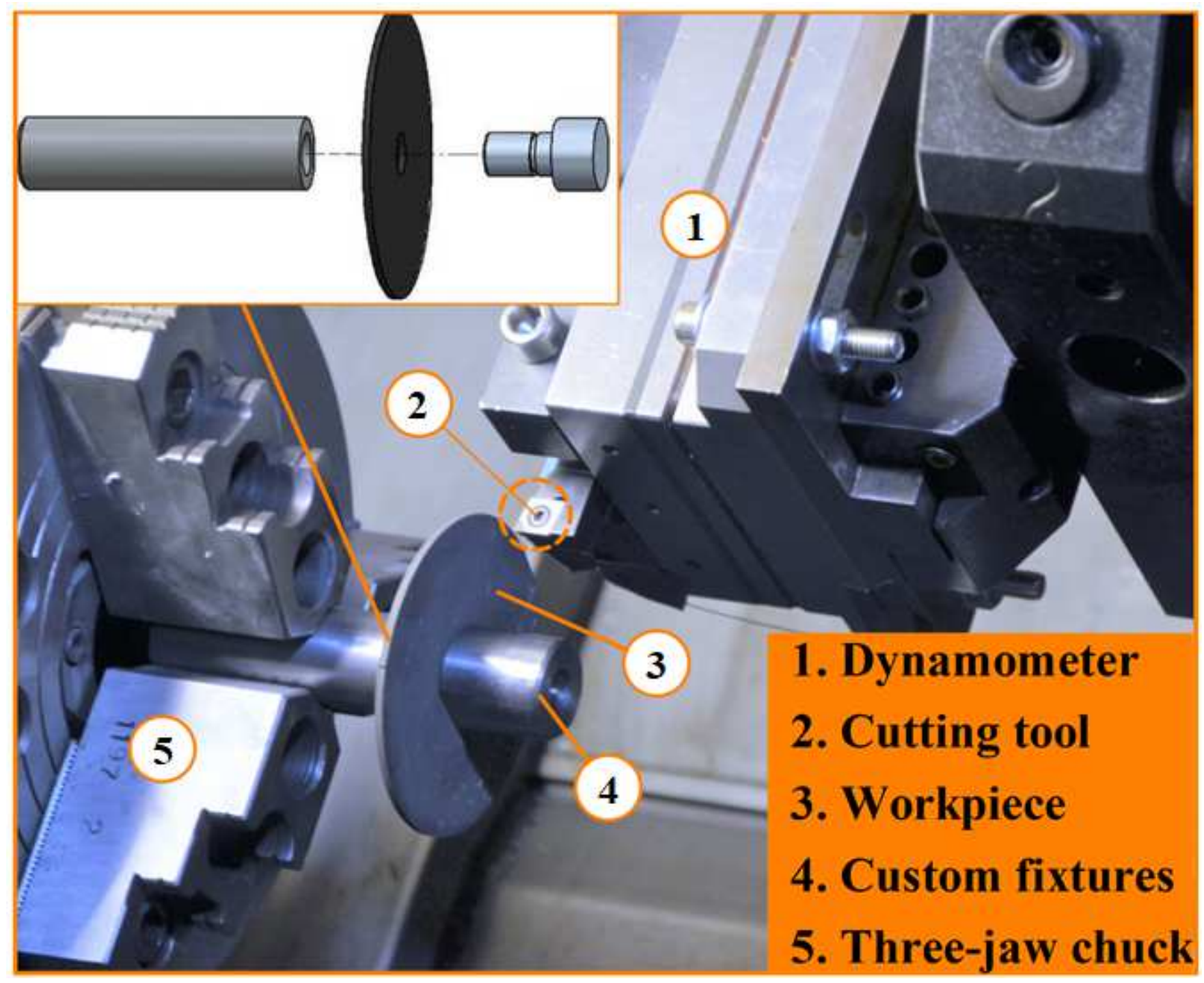

Figure 2

Experimental setup details. 


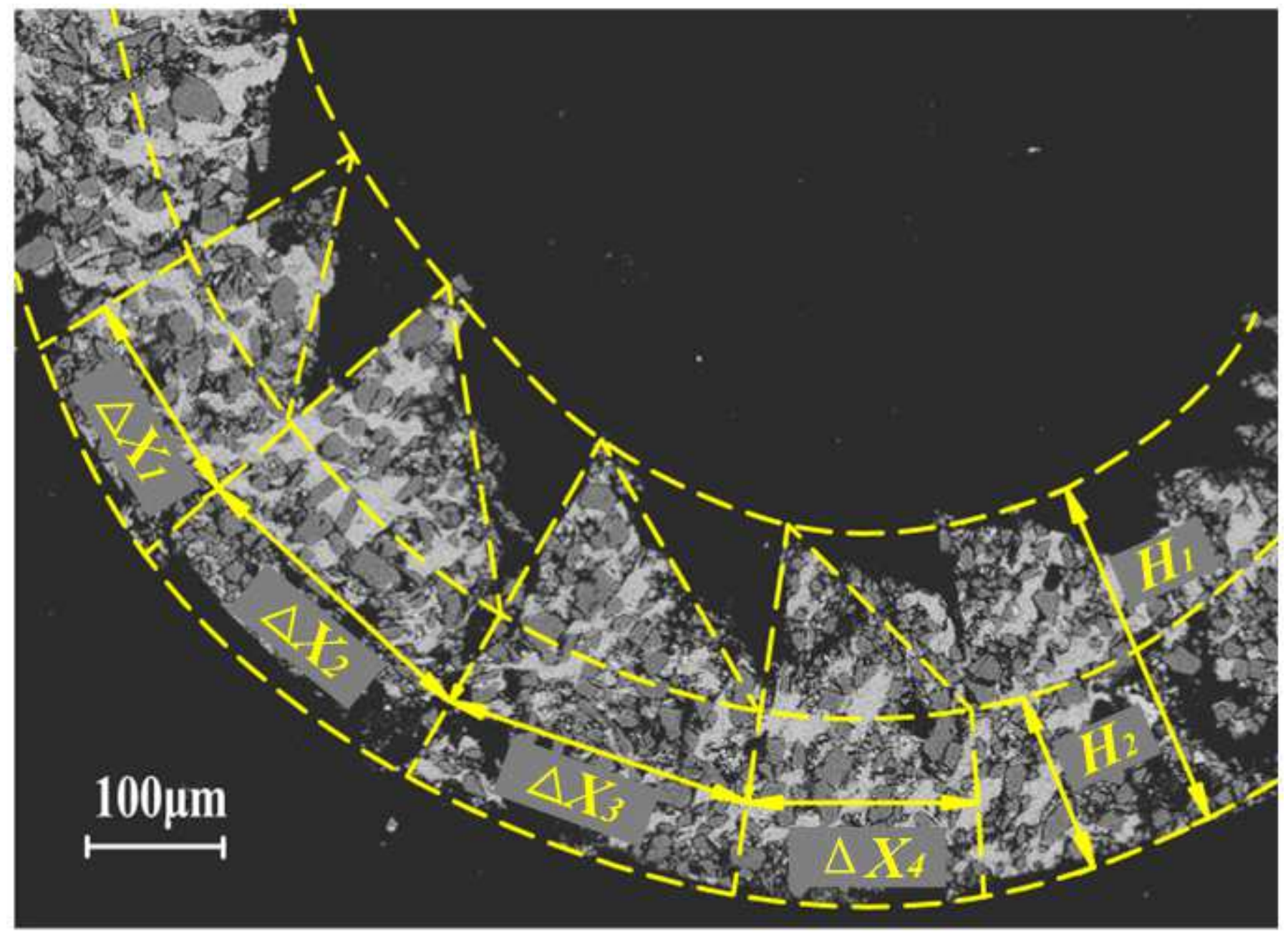

Figure 3

Schematic showing chip measurement. 


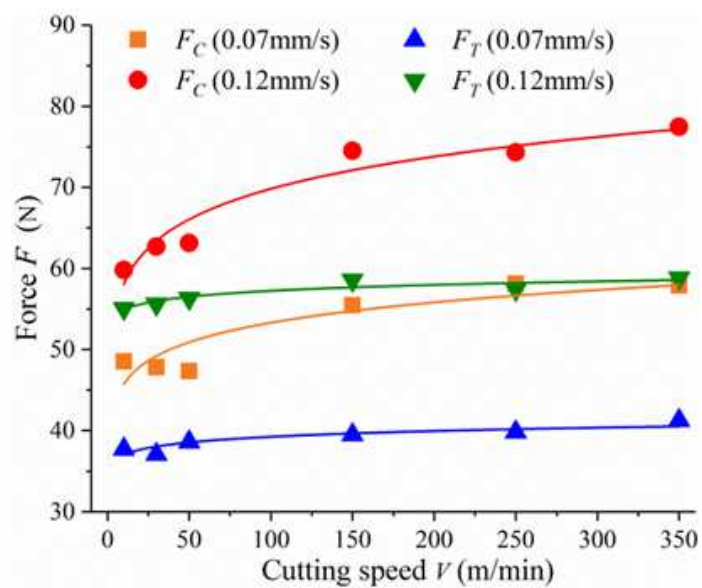

(a)

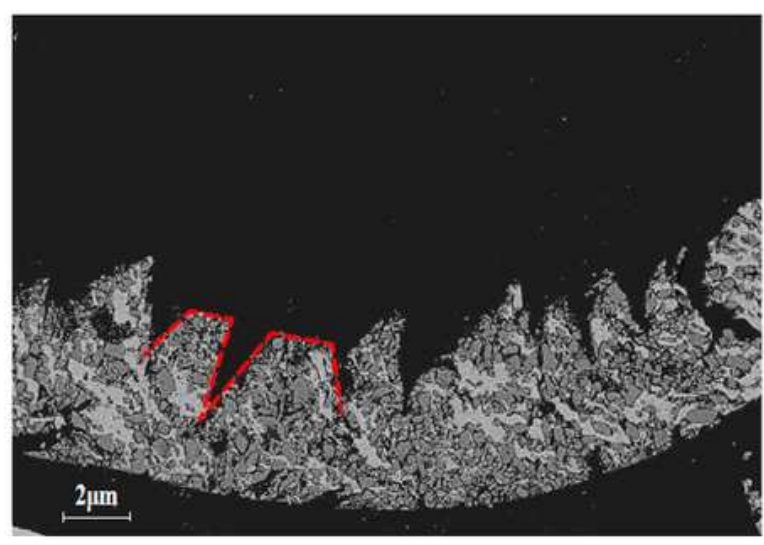

(c)

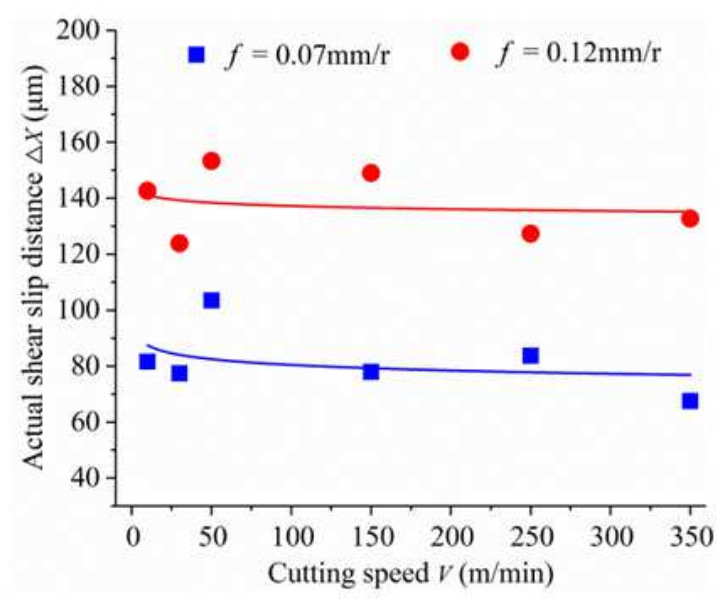

(e)

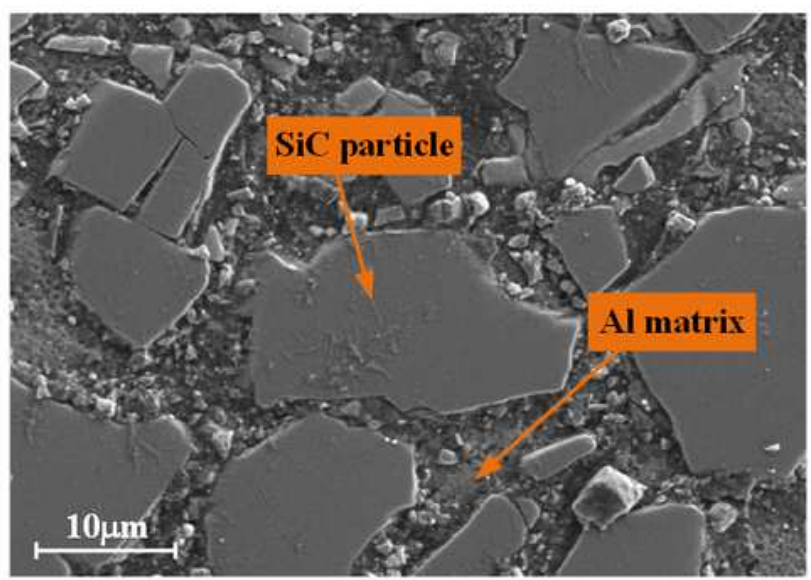

(b)

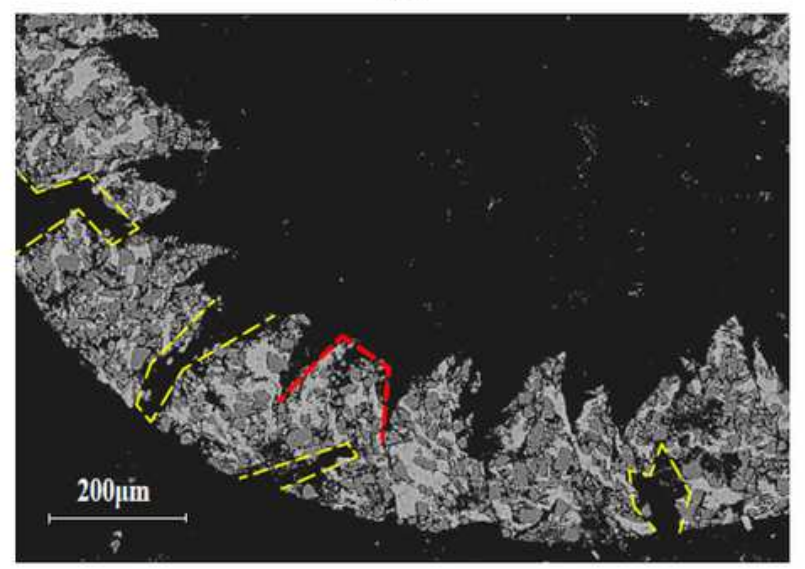

(d)

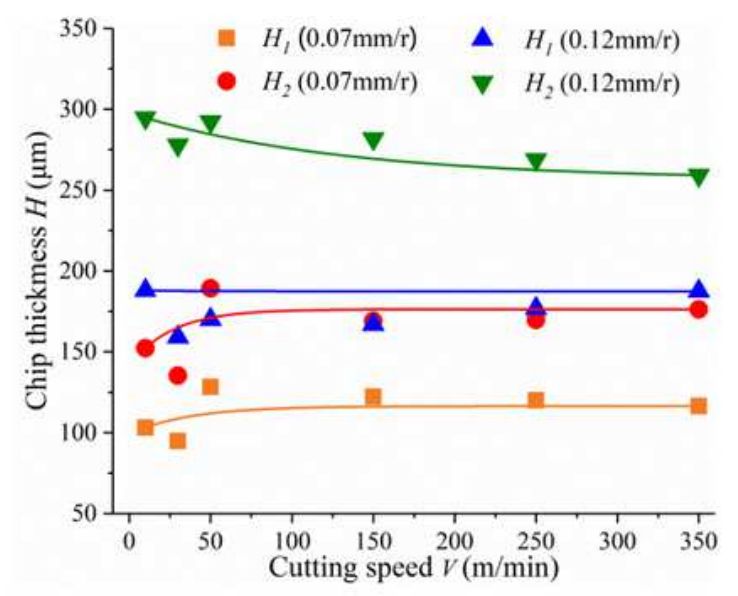

(f)

\section{Figure 4}

Basic parameters: (a) force, (b) SEM image of chip subjected to $0.07 \mathrm{~mm} / \mathrm{r}$ and $30 \mathrm{~m} / \mathrm{min}$ after the experiment, (c) $₫($ d) SEM image of chip subjected to $0.12 \mathrm{~mm} / \mathrm{r}$ and $30 \mathrm{~m} / \mathrm{min}$, (e) actual slip distance and (f) chip thickness. 


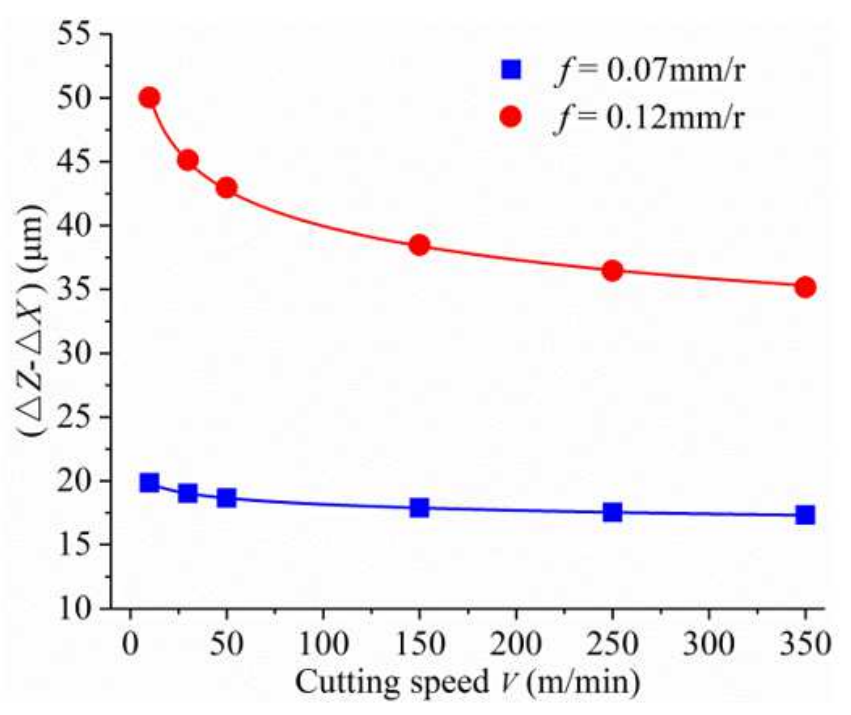

(a)

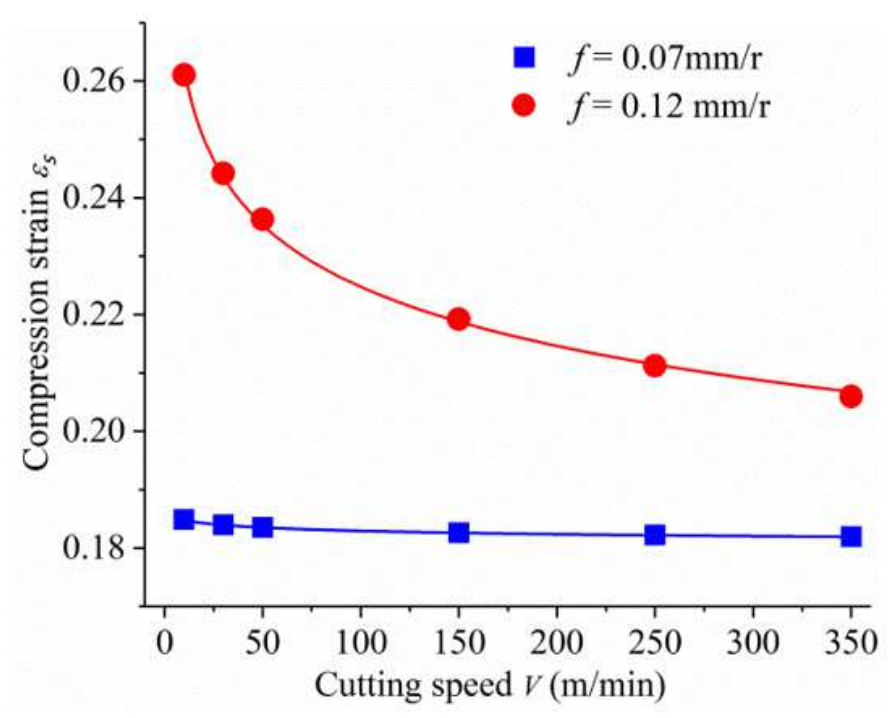

(c)

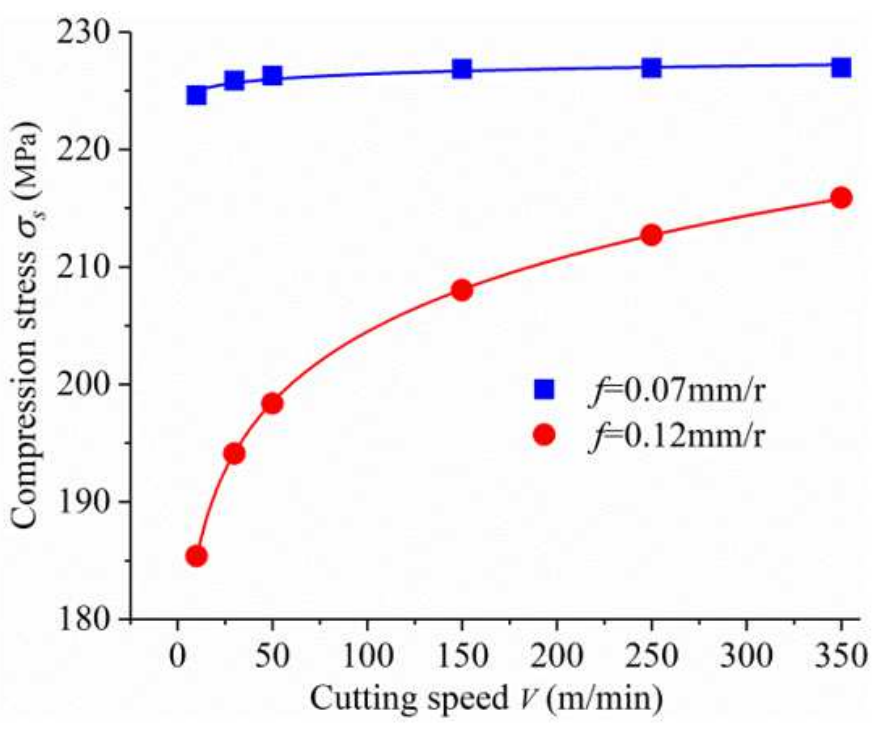

(b)

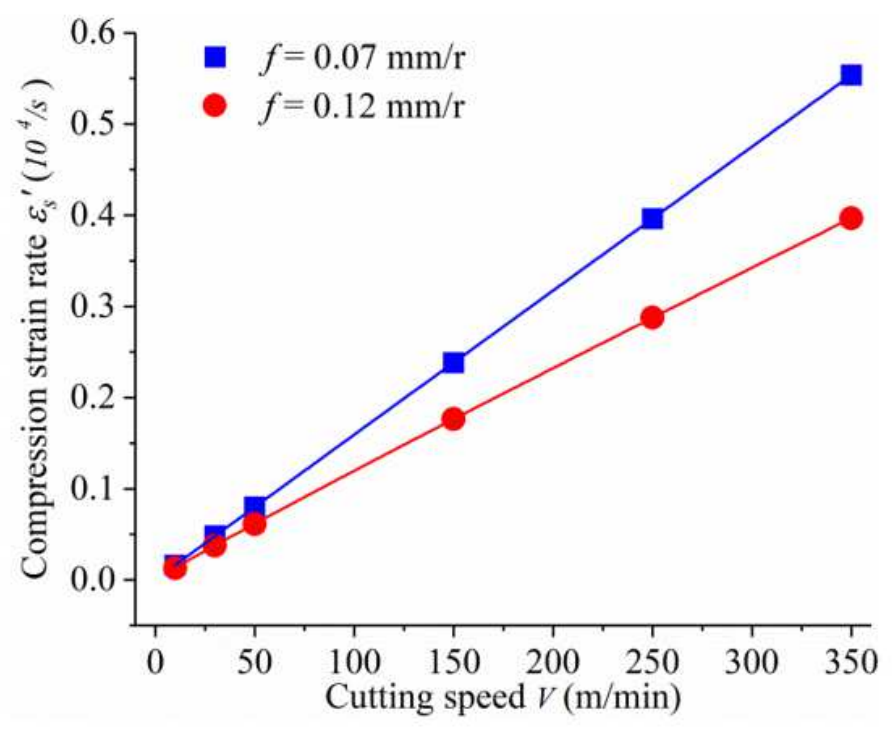

(d)

\section{Figure 5}

Values of the (a) compressive value, (b) compressive stress, (c) compressive strain, and (d) compressive strain rate 


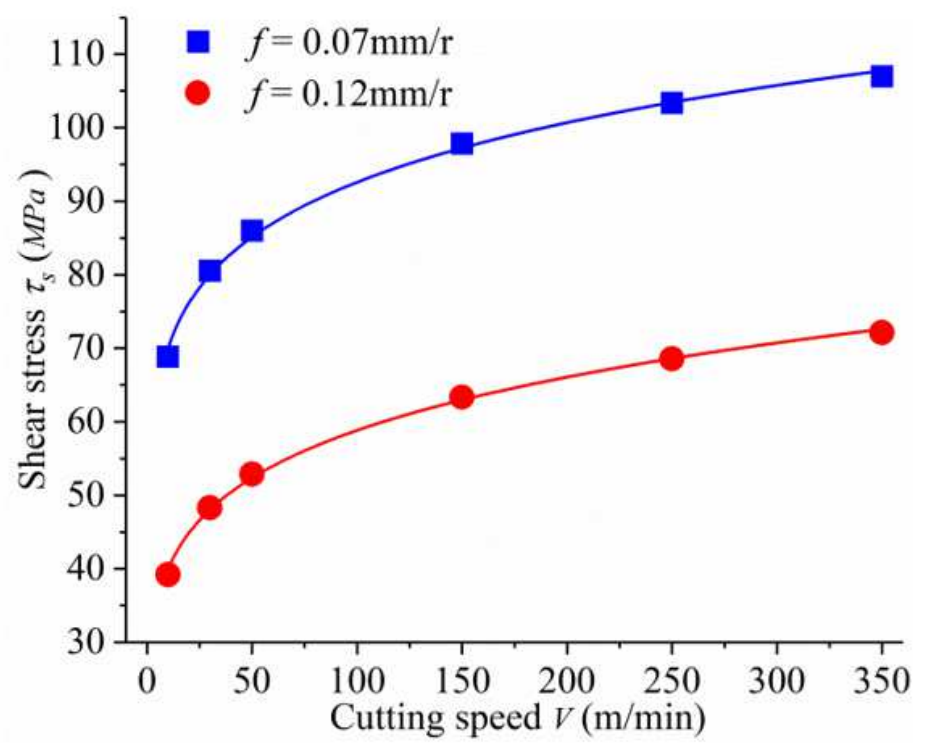

(a)

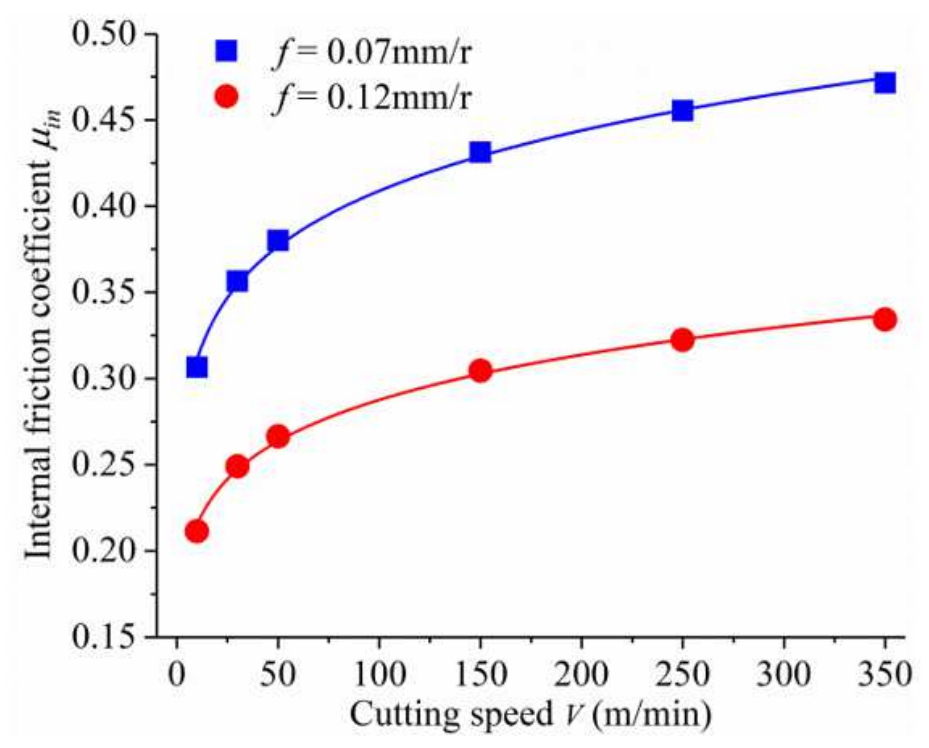

(b)

Figure 6

(a) Shear stress and (b) internal friction coefficient. 